\title{
Clinical outcomes of 77 TESE treatment cycles in non-mosaic Klinefelter syndrome patients
}

\author{
Pedro Barros ${ }^{1}$, Mariana Cunha ${ }^{2}$, Alberto Barros ${ }^{1,2,3}$, Mário Sousa ${ }^{4,5, *}$, Sofia Dória ${ }^{1,3, *}$ \\ ${ }^{1}$ Department of Genetics, Faculty of Medicine, University of Porto, Porto, Portugal \\ ${ }^{2}$ Centre for Reproductive Genetics A. Barros, Porto, Portugal \\ ${ }^{3}$ Institute of Health Research and Innovation (IPATIMUP/i3S), University of Porto, Porto, Portugal \\ ${ }^{4}$ Laboratory of Cell Biology, Department of Microscopy, Institute of Biomedical Sciences Abel Salazar (ICBAS), \\ University of Porto, Porto, Portugal \\ ${ }^{5}$ Unit for Multidisciplinary Investigation in Biomedicine, ICBAS-UP, Porto, Portugal
}

*The authors contributed equally to this study.

\begin{abstract}
Objective: The current study aimed to present the clinical outcomes of 76 azoospermic patients with non-mosaic Klinefelter syndrome (KS), treated with testicular spermatozoa extraction (TESE) followed by intracytoplasmic sperm injection (ICSI) using either fresh or cryopreserved testicular spermatozoa.
\end{abstract}

Methods: We retrospectively evaluated 76 patients with non-mosaic KS belonging to a special group of cases that besides infertility did not present the classical signs and symptoms of testosterone deficiency. One of the patients repeated the TESE procedure (76 patients, 77 TESE cycles). Sixty of these 76 patients accepted to undergo TESE associated with ovarian stimulation, while 16 patients underwent TESE followed by testicular spermatozoa cryopreservation. Aneuploidy screening of the offspring was performed by Multiplex ligation-dependent probe amplification and by amniotic fluid karyotyping. Statistical analysis used the Chi-Squared Test, Fisher's Exact Test, 2-sided, for rates, and the Independent Samples T-test for equality of means, 2-sided.

Results: Testicular spermatozoa were recovered in 31 $(40.3 \%)$ of the attempts. The patients underwent 47 ICSI cycles, 25 with fresh testicular spermatozoa and 22 with cryopreserved testicular spermatozoa. Fertilization $(63.5 \%$ vs. $41.6 \%, p=0.000)$, implantation ( $37 \%$ vs. $13.2 \%$, $p=0.014)$, clinical pregnancy $(60.9 \%$ vs. $19 \%, p=0.005)$ and live birth $(65.2 \%$ vs. $23.8 \%, p=0.006)$ rates were higher with fresh testicular spermatozoa. Chromosome analysis of the 21 newborns was normal.

Conclusions: The present data adds further information regarding the recovery rate of spermatozoa after TESE and the embryological and clinical outcomes with fresh and cryopreserved testicular spermatozoa, besides reassuring the safety concerning chromosomal transmission of $\mathrm{KS}$ from parents to their offspring.

Keywords: azoospermia, clinical outcomes, non-mosaic Klinefelter syndrome, testicular spermatozoa extraction, newborn

\section{INTRODUCTION}

Klinefelter syndrome (KS) is a male hypergonadotropic hypogonadism (Klinefelter et al., 1942) caused by the presence of an extra $X$ chromosome (Jacobs \& Strong, 1959). The classical phenotype is characterized by small firm testes, gynecomastia, eunuchoid body proportions, high levels of gonadotropins (FSH, LH), low/normal levels of testosterone, and progressive testicular insufficiency causing androgen deficiency (Groth et al., 2013). The syndrome affects about $0.15 \%$ of male newborns in the general population (Gravholt et al., 2018). The most common karyotype is $47, \mathrm{XXY}(80-90 \%$ of the cases), being the mosaic form $(47, X X Y$ in combination with a normal $46, X Y$ line or other aneuploid lines) less frequent (10-20\% of the cases) (Lanfranco et al., 2004), with the supernumerary $\mathrm{X}$ chromosome derived from male or female nondisjunction errors at the first meiotic division (Thomas \& Hassold, 2003). In KS patients, hormone levels and testicular morphology vary from the fetal period to adulthood. Gradual increases in FSH and $\mathrm{LH}$ levels have been observed, along with decreases in Inhibin and Anti-Müllerian hormone $(\mathrm{AMH})$ levels, maintenance of testosterone and Insulin-like factor-3 (INSL3) levels (Aksglaede et al., 2006), a gradual loss of spermatogonia with loss of functional seminiferous tubules, fibrosis and hyalinization of the interstitium, and Leydig cell hyperplasia (Wikström \& Dunkel, 2008; Van Saen et al., 2018).

Patients with KS present a broad spectrum of phenotypes, with different severity degrees of androgen deficiency, mainly because of the non-inactivation of several critical X-linked genes (Bonomi et al., 2017). This enables the existence of testicular foci with preserved spermatogenesis. In these cases, cytogenetic studies revealed the presence of spermatogonia lines with a 47,XXY and/or $46, X Y$ chromosome constitution, with the presence of haploid spermatozoa derived from both spermatogonia lines (Sciurano et al., 2009; Garcia-Quevedo et al., 2011; Miki et al., 2017). Testicular sperm extraction (TESE) applied to KS patients revealed foci of spermatogenesis in about $40 \%$ of the cases, with testicular sperm then used in infertility treatments (Tournaye et al., 1996; Palermo et al., 1998).

Only three studies have reported on a large number of KS patients whose infertility treatments included cryopreserved testicular spermatozoa (Greco et al., 2013; Madureira et al., 2014; Vicdan et al., 2016). In the present report, we evaluated 76 azoospermic patients with non-mosaic KS that accepted to undergo treatment with TESE-ICSI. All patients belong to a group of cases referred only due to infertility, without classical signs and symptoms of testosterone deficiency. Patient characteristics, testicular sperm retrieval rates and clinical outcomes after treatment with fresh and frozen-thawed testicular spermatozoa were analyzed. There were 21 newborns, all healthy and without chromosomal abnormalities.

\section{MATERIALS AND METHODS}

\section{Ethics guidelines}

This study did not involve experimentation with humans or animals. Patient data were used only with a statistical purpose. According to the National Law on Medically Assisted Procreation (Law 32/2006) and the National Council for Medically Assisted Procreation guidelines (2018), the 
use of clinical databases for research is allowed without need for approval by an Ethics Committee, as long as the data is anonymized and patients give consent in written. Data collection followed the principles outlined in the Declaration of Helsinki. All men previously gave informed consent agreeing to share their anonymized information for future studies. The University Hospital Ethics Committee approved the study and assigned it certificate number 2019/CE/P017 (266/CETI/ICBAS). Patients were informed of the technical possibility of preimplantation genetic testing for aneuploidy and of prenatal diagnosis.

\section{Patients}

We retrospectively evaluated 139 patients with azoospermia due to non-mosaic KS seen in consecutive years (1994-2019). These patients belong to a special category of KS, since all went to private IVF clinics due to infertility in adult age, without showing the classical signs and symptoms of testosterone deficiency. None of the patients had ever received hormone replacement therapy. The same urologist evaluated all KS patients and performed the testicular biopsies. The genetic analysis of KS patients and their offspring was performed at a University Department of Genetics. Clinical diagnosis was based on the absence of sperm in semen, confirmed after centrifugation, decreased testicular volume and increased serum levels of FSH and $\mathrm{LH}$, and karyotype confirmation of the $47, \mathrm{XXY}$ status.

Karyotypes were obtained using $\mathrm{G}$ banding, with analysis of at least 30 metaphases from peripheral blood lymphocytes in accordance to general protocols (Rooney \& Czepulkowski, 1997). Aneuploidy screening of the offspring was performed in 18 cases by Multiplex ligation-dependent probe amplification (MLPA) for chromosomes 13, 18, 21, $X$ and $Y$, using oral epithelial cells obtained at the postnatal period in 17 cases and DNA extracted from paraffin blocks in one case of a neonatal death. In the remaining 3 cases, prenatal diagnosis was performed and karyotypes were obtained from amniotic fluid. DNA extraction from oral epithelial cells was performed using a commercial kit (JETQUICK, Blood \& Cell Culture DNASpin Kit; Genomed, Lohne, Germany). DNA extraction from paraffin-embedded material was performed using the DNeasy Blood and Tissue Kit (QIAGEN, Hilden, Germany). Aneuploidy screening was performed using the MLPA technique (Kit SALSA P095; MRC-Holland, Amsterdam, The Netherlands) (Schouten et al., 2002).

The volume of each testis was determined by two sequential methods, one using the Prader orchidometer (12 ellipsoid solid models of 1-25 ml) and the other an orchidometer with ellipsoid rings of 1-30 ml. The testicular volumes were considered atrophic when the volume was $<6 \mathrm{ml}$, hypotrophic when between 6-15 ml, and normal when >15ml (Bujan et al., 1989).

Of the 139 patients, 76 accepted to undergo treatment by TESE, and one repeated the TESE procedure (76 patients, 77 TESE cycles). Sixty of these 76 patients accepted to undergo TESE associated with ovarian stimulation, once they planned to use donor sperm in case of testicular sperm retrieval failure. The other 16 patients underwent diagnostic TESE followed by testicular sperm cryopreservation. The latter cases preferred to postpone ovarian stimulation, as they did not intend to use donor sperm in case of testicular sperm retrieval failure. The outcomes of these 76 patients were the object of the present study.

\section{Testicular biopsy}

We performed open testicular biopsies by testicular spermatozoa extraction (TESE), where a single small surgical window allows the collection of testicular tissue at different levels. A microscope was not needed in the operating room. We used a local nerve anesthetic protocol (Sousa et al., 2002; Madureira et al., 2014). Spermatic cord block was performed according to the three-finger technique ( $\mathrm{Li}$ et al., 1992; Gorgy et al., 1998; Nudell et al., 1998). Local anesthesia was achieved with $5-10 \mathrm{ml}$ of a $1: 1 \mathrm{mix}-$ ture of $1 \%$ lidocaine hydrochloride solution (Xylocaine $2 \%$ without epinephrine; rapid action) and $0.5 \%$ bupivacaine (Marcaine $0.5 \%$ without epinephrine; long action). More recently, we have used $10 \%$ ropivacaine instead of bupivacaine, since it has a longer action period, enabling local discomfort relief for 2-3 h. In cases where the patient was more tolerant, anesthesia was performed only with $10 \%$ ropivacaine.

After a few minutes (about $5 \mathrm{~min}$ ), a skin weal was raised in the scrotum adjacent to the middle region of the testis. A $1 \mathrm{~cm}$ transverse incision was then made and the tunica vaginalis space was entered. An incision of $0.5 \mathrm{~cm}$ then enabled the excision of a small piece of the seminiferous tubules $(1-2 \mathrm{~mm})$. A preliminary microscopic check of the sample (observation in an inverted research microscope, equipped with Hoffman optics and operated at room temperature) at the end of each biopsy avoided unnecessary tissue sampling. For this, each fragment was collected in Sperm Preparation Medium (SPM-Hepes; Origio, Jyllinge, Denmark) and then gently fragmented and squeezed to release luminal epithelial cells. Whenever needed and possible, the contralateral testis was biopsied. At the end of the biopsy procedure, and after careful cleaning and hemostasis, the tunica albuginea, the vaginal, the scrotum layers and the skin were closed. The procedure took about 30-45 minutes and was performed entirely on an outpatient basis. The procedure enabled rapid recovery with minimal complains and total absence of surgical complications, and none of the patients required hormone replacement therapy postoperatively. Oral tramadol and paracetamol were given to relieve discomfort in the first 24 h. When another biopsy was needed (one case), the procedure was scheduled to six months later to enable local repair and reestablishment of the vascular supply (Schlegel \& Su, 1997).

The testicle with the highest volume was biopsied first. Testicular biopsy was mainly unilateral $(87 \%$ of the cases, $67 / 77$ ) and was performed on the right testicle in $68.8 \%$ $(53 / 77)$ of the cases, on the left testicle in $18.2 \%(14 / 77)$ of the cases, and bilaterally in $13 \%(10 / 77)$ of the cases.

In cases with successful spermatozoa retrieval, testicular biopsy was unilateral in $96.8 \%(30 / 31)$ of the cases. The procedure was performed on the right testicle in $64.5 \%(20 / 31)$ of the cases, on the left testicle in $32.3 \%$ $(10 / 31)$ of the cases, and bilaterally in $3.2 \%(1 / 31)$ of the cases.

In cases without successful spermatozoa retrieval, testicular biopsy was unilateral in $80.4 \%(37 / 46)$ of the cases. Biopsy was performed on the right testicle in $71.7 \%$ $(33 / 46)$ of the cases, on the left testicle in $8.7 \%(4 / 46)$ of the cases, and bilaterally in $19.6 \%(9 / 46)$ of the cases.

At the laboratory, seminiferous tubule fragments were sorely mechanically fragmented and squeezed under a heated stereomicroscope to release luminal epithelial cells (Verheyen et al., 1995). If a good number of spermatozoa was obtained, the fluid fraction resulting from mechanical dissection was used for spermatozoa selection to ICSI. If the sample was contaminated with erythrocytes, the fluid fraction resulting from mechanical dissection was washed in SPM ( $2 \times 5 \mathrm{~min}, 300 \mathrm{~g})$ and the resulting cell pellet incubated for $5 \mathrm{~min}\left(37^{\circ} \mathrm{C}, 5 \% \mathrm{CO}_{2}\right.$, filtrated humidified air) in $2 \mathrm{ml}$ erythrocyte-lysing buffer $\left[155 \mathrm{mM} \mathrm{NH}_{4} \mathrm{Cl}, 10 \mathrm{mM}\right.$ $\mathrm{KHCO}_{3}, 2 \mathrm{mM}$ EDTA, in water, pH 7.2 with $\mathrm{KOH}, 0.2 \mu \mathrm{m}$ filtered (Millipore); endotoxin free, embryo and cell culture tested; Sigma, Barcelona, Spain)], followed by the addition of $2 \mathrm{ml}$ SPM. The cell suspension was then washed in SPM ( $2 \times 5 \mathrm{~min}, 300 \mathrm{~g})$ and the cell pellet resuspended 
in SPM (Verheyen et al., 1995). Mechanical fragmentation and squeezing, and the use of the erythrocyte-lysing buffer were previously shown to enhance the efficiency of sperm selection without affecting sperm vitality or embryological and clinical outcomes (Verheyen et al., 1995; Nagy et al., 1997).

When a lower number of spermatozoa was retrieved, the fluid fraction resulting from mechanical dissection was treated with erythrocyte-lysing buffer and enzymatically digested. For tissue digestion, the resulting cell pellet was washed in SPM $(2 \times 5 \mathrm{~min}, 500 \mathrm{~g})$ and the pellet digested for $20 \mathrm{~min}$ [ $25 \mu \mathrm{g}$ crude DNase, 1000 units collagenase-IV (Sigma) in $1 \mathrm{ml} \mathrm{SPM]} \mathrm{in} \mathrm{the} \mathrm{incubator}\left(37^{\circ} \mathrm{C}, 5 \% \mathrm{CO}_{2}\right.$, filtrated humidified air). Cells in the suspension were then separated ( $5 \mathrm{~min}, 50 \mathrm{~g}$ ) into supernatant (mainly haploid germ cells) and pellet (mainly diploid germ cells and a few Sertoli cells) fractions. The fractions were then washed with SPM ( $2 \times 5 \mathrm{~min}, 1000 \mathrm{~g})$, and the final pellets were resuspended in $100 \mu \mathrm{l}$ of SPM, followed by incubation at $32^{\circ} \mathrm{C}$ until use.

Observations were performed on the thermal stage $\left(32^{\circ} \mathrm{C}\right)$ of an inverted microscope (Nikon DIAPHOT 200; Nikon, Tokyo, Japan) equipped with Hoffman optics (Nikon) and Narishige micromanipulators (MO-188; Narishige, Tokyo, Japan). To search for spermatozoa, 10-20 $\mu$ l of the cell suspension were diluted in a 20-30 $\mu$ SPM microdrop placed in a sterile cell culture plastic Petri dish $(60 \mathrm{~mm}$, Falcon), under paraffin oil (Origio), which was then spread to facilitate the search. When spermatozoa were found, they were transferred to another SPM microdrop using microinjection needles $(0.009 \mathrm{~mm}$; Swemed, Goteborg, Sweden). In difficult cases, the search for motile spermatozoa took several hours. Enzymatic digestion followed published protocols, which also showed to enhance the efficiency of spermatozoa selection while not affecting spermatozoa vitality or embryological and clinical outcomes (Crabbé et al., 1997; 1998).

\section{Testicular sperm cryopreservation and thawing}

In cases with a good number of surplus spermatozoa, the fluid was cryopreserved. In cases with low spermatozoa numbers, the fluid was enzymatically digested and the two fractions, supernatant and resuspended pellet, were cryopreserved separately. In cases with only a few surplus spermatozoa, cryopreservation was not performed. Testicular sperm suspensions $(250 \mu \mathrm{l})$ were mixed to a $1: 1$ dilution with $250 \mu \mathrm{l}$ of Sperm-Freezing-Medium or Cryosperm (Måløv, Denmark) and left to equilibrate for 10 min at room temperature. The cell suspensions were then aspirated into labeled straws, sealed ( $L^{\prime}$ Aigle, France), left over LN2 vapor (30 $\mathrm{min}$ ), and then immersed and stored in LN2. For thawing, straws were left for $15 \mathrm{~min}$ at room temperature and then washed with SPM $(2 \times 10 \mathrm{~min}, 500$ g). The pellet was then resuspended in $50-100 \mu$ of SPM and an extensive search for motile spermatozoa followed.

\section{Ovarian stimulation}

Women underwent controlled ovarian hyperstimulation with a GnRH antagonist protocol in the majority of the cases (Merck Serono, Geneve, Switzerland; Organon, Oss, Netherlands) and with an agonist protocol in the remaining cases (Sanofi Aventis, Frankfurt, Germany). For stimulation, recombinant follicle stimulating hormone ( $\mathrm{rFSH})$ was used in most cases (Organon; Merck Serono), while human menopausal gonadotropin (HMG) was used as an alternative (Ferring, Kiel, Germany). Ovulation trigger was performed either with human chorionic gonadotropin (Organon) or recombinant HCG (Merck-Serono). Estradiol serum levels were analyzed on the day of HCG or one day before (Pinto et al., 2009).

\section{Gamete and embryo handling}

Gametes and embryos were handled with media from Origio (Jyllinge, Denmark) or Vitrolife (Kungsbacka, Sweden). Microinjection was performed in an inverted microscope (Nikon DIAPHOT 200; Nikon, Tokyo, Japan) with Narishige micromanipulators (MO-188; Narishige, Tokyo, Japan), using micropipettes from Swemed (Goteborg, Sweden). ICSI was performed using strong dislocation of the cytoplasm (Tesarik \& Sousa, 1995). Cleavage embryos (Vandervorst et al., 1998) and blastocysts (Gardner et al., 2000) were graded based on the Istanbul consensus (AIpha Scientists in Reproductive Medicine and ESHRE Special Interest Group of Embryology, 2011). Ultrasound guided embryo transfer was performed with a Sure View Wallace Embryo Replacement Catheter or Wallace malleable stylet (Smiths Medical Int, Kent, UK).

\section{Luteal supplementation}

Luteal supplementation was accomplished with intravaginal administration of $600 \mathrm{mg}$ daily (200 mg, tid) of natural micronized progesterone (Jaba, Besins Int, Montrouge, France) beginning on the day of oocyte retrieval. Implantation was confirmed by a rise in serum BHCG 12 days after embryo transfer. Clinical pregnancy was established by ultrasound at 6 weeks of gestation. Progesterone was maintained until $\beta$ HCG serum assay and, if positive, it was continued until 8 weeks of gestation.

\section{Statistical analysis}

Statistical analysis was performed with the IBM SPSS Statistics 20 program for Windows, using the Chi-Squared Tests, Fisher's Exact Test, 2-sided and the Independent Samples T-test for equality of means, 2 -sided. A value of $p<0.05$ was considered statistically significant.

\section{RESULTS}

\section{Testicular biopsy and patient characteristics}

One of the 76 patients with non-mosaic KS repeated the TESE procedure. Testicular spermatozoa were recovered in $31 / 77(40.3 \%)$ of the cases. TESE was performed in 61 of the 77 cases $(25 / 61,41 \%$ of sperm retrieval rate) in stimulated cycles, since couples accepted to use donor sperm if sperm retrieval on TESE failed; and 16 cases performed diagnostic TESE $(6 / 16,37.5 \%$ of sperm retrieval rate) outside a stimulated cycle with couples who refused to use donor sperm. In the latter cases, spermatozoa were cryopreserved. Patients unable to retrieve spermatozoa decided either for no treatment ( 9 cases) or to use donor spermatozoa (37 cases). Three of the 46 cases in which spermatozoa retrieval was unsuccessful presented maturation arrest at the primary spermatocyte stage and 43 had Sertoli cell only syndrome.

Comparisons between the 31 cases of successful spermatozoa retrieval and the 46 cases of failed TESE revealed no significant differences regarding male partner mean age $(p=0.356)$, time of infertility $(p=0.706)$, testicular volume $(p=0.479)$, serum levels of FSH $(p=0.660)$, LH $(p=0.362)$ and testosterone $(p=0.089)$, total number of testicular fragments $(p=0.596)$ analyzed, or time of search $(p=0.138)$ in samples (Table 1 ). Male partner mean age was $34.1 \pm 4.1$ (range: 26-46) years. In cases resulting in live births, male partner mean age was $33.6 \pm 3.0(28-38)$ years.

Testicular volume was decreased in $96.1 \%$ of all cases; $40.3 \%$ were atrophic, $55.8 \%$ were hypotrophic, and $3.9 \%$ were normal. Testicular volume was decreased in $96.8 \%$ of the cases with successful sperm retrieval; $38.7 \%$ were atrophic, $58.1 \%$ were hypotrophic, and $3.2 \%$ were normal. Testicular volume was decreased in $95.7 \%$ of the cases of failed TESE; $41.3 \%$ were atrophic, $54.4 \%$ were hypotrophic, and $4.4 \%$ were normal. 
Table 1. Clinical data of patients with non-mosaic Klinefelter syndrome submitted to TESE.

\begin{tabular}{|l|c|c|c|c|}
\hline Parameters & $\begin{array}{c}\text { TESE with sperm } \\
\text { retrieval }\end{array}$ & $\begin{array}{c}\text { TESE without sperm } \\
\text { retrieval }\end{array}$ & $\boldsymbol{p}$ value a & Total \\
\hline TESE $(\mathrm{n})$ & 31 & 46 & 77 \\
\hline Male age (years) & $33.5 \pm 3.8(28-46)$ & $34.4 \pm 4.3(26-42)$ & 0.356 & $34.1 \pm 4.1(26-46)$ \\
\hline Time of infertility (years) & $3.8 \pm 2.4(1-10)$ & $4.1 \pm 3.6(1-17)$ & 0.706 & $4.0 \pm 3.2(1-17)$ \\
\hline Total testicular volume (ml) & $7.3 \pm 3.7(3-16)$ & $8.0 \pm 4.4(3-16)$ & 0.479 & $7.7 \pm 4.2(3-16)$ \\
\hline FSH (mIU/ml) & $29.6 \pm 16.2(11.8-62.2)$ & $31.1 \pm 9.8(10.4-54.2)$ & 0.660 & $30.5 \pm 12.6(10.4-62.2)$ \\
\hline LH (mIU/ml) & $16.6 \pm 5.9(4.4-29.4)$ & $18.5 \pm 8.3(1.9-50)$ & 0.362 & $17.7 \pm 17.3(1.9-50)$ \\
\hline Testosterone (ng/ml) & $7.0 \pm 4.8(2.42-18)$ & $10.7 \pm 9.0(2.45-30.86)$ & 0.089 & $9.1 \pm 7.6(2.42-30.86)$ \\
\hline Number of Fragments Biopsied & $8.1 \pm 3.2(2-18)$ & $7.7 \pm 2.9(3-15)$ & 0.596 & $7.9 \pm 3.1(2-18)$ \\
Total & $8.0 \pm 3.8(2-18)$ & $7.1 \pm 2.5(2-13)$ & 0.297 & $7.4 \pm 3.0(2-18)$ \\
Right Testicle & $7.6 \pm 2.7(3-12)$ & $4.3 \pm 1.9(1-8)$ & 0.002 & $5.8 \pm 2.8(1-12)$ \\
Left Testicle & $3.5 \pm 3.0(0.5-16)$ & $4.1 \pm 0.7(1.5-5)$ & 0.138 & $3.9 \pm 2.0(0.5-16)$ \\
\hline Time of Search & & & & \\
\hline
\end{tabular}

Values in: mean \pm SD, (range).

TESE $=$ testicular sperm extraction

$\mathrm{n}=$ number of TESE cases

FSH (normal range: $0.7-11.1 \mathrm{mIU} / \mathrm{ml}$ )

LH (normal range: 0.8-7.6 mIU/ml),

Testosterone (normal range: $2.45-16 \mathrm{ng} / \mathrm{ml}$ ),

Significant differences between groups with and without sperm retrieval $(p<0.05)$.

Testicular volume was decreased in $92.3 \%$ of the cases that resulted in live births.

Mean serum FSH levels were increased in $98.3 \%$ of all cases; $1.7 \%$ had normal levels and none had decreased $\mathrm{FSH}$ levels. Mean FSH levels were increased in all cases $(100 \%)$ with successful sperm retrieval. Mean FSH levels were increased in $97.2 \%$ of the cases of failed TESE; $2.8 \%$ had normal levels and none had decreased FSH levels. Mean FSH serum levels were increased in all cases that resulted in live births.

Mean serum LH levels were increased in $94.1 \%$ of all cases; $5.9 \%$ had normal levels and none had decreased $\mathrm{LH}$ levels. Mean LH serum levels were increased in $90.9 \%$ of the cases with successful sperm retrieval; $9.1 \%$ had normal levels and none had decreased LH levels. Mean LH serum levels were increased in $96.6 \%$ of the cases of failed TESE; $3.4 \%$ had normal levels and none had decreased LH levels. Mean LH serum levels were increased in $81.8 \%$ of the cases that resulted in live births.

Mean serum testosterone levels were normal in $77.6 \%$ of all cases; $20.4 \%$ had increased levels and $2 \%$ had decreased serum testosterone levels. In cases with successful TESE, the Mean serum testosterone levels were normal in $85.7 \%$ of the cases with successful TESE; $9.5 \%$ had increased levels and $4.8 \%$ had decreased serum testosterone levels. Mean serum testosterone levels were normal in $71.4 \%$ of the cases with failed TESE; $28.6 \%$ had increased levels and none had decreased testosterone levels. Mean serum testosterone levels were normal in $91.7 \%$ of the cases that resulted in live births. The patient with decreased testosterone levels presented borderline values (one TESE cycle, one female newborn).

\section{Embryological, clinical and newborn outcomes}

A total of 47 ICSI treatment cycles were performed in the 31 patients with successful spermatozoa retrieval. Twenty-five cycles ( 23 with embryo transfer) used fresh testicular spermatozoa and 22 (21 with embryo transfer) used frozen-thawed testicular spermatozoa, adding up to 44 cycles with embryo transfer. Seventeen used cryopreserved spermatozoa from the surplus spermatozoa originated from TESE cases using fresh spermatozoa in the first attempt and five cases from diagnostic TESE. Three of the six cases with successful spermatozoa retrieval during diagnostic TESE had one treatment cycle with cryopreserved spermatozoa; one case had two cycles with cryopreserved spermatozoa; and two cases declined treatment, which yielded $22(17+5)$ ICSI cycles with cryopreserved testicular spermatozoa.

In terms of embryological outcomes (Table 2), no significant differences between fresh and cryopreserved spermatozoa were found in relation to the mean number of cumulus-oocyte complexes $(p=0.419)$ or mature oocytes $(p=0.561)$ retrieved, or in oocyte maturation rate $(80.3 \%$ vs. $82.2 \%, p=0.611$ ). Cycles with fresh spermatozoa yielded a significantly greater mean number of fertilized oocytes $(p=0.013)$ and higher fertilization rate $(63.5 \% \mathrm{vs}$. $41.6 \%, p=0.000)$. Although the mean number of cleaved embryos was significantly higher in cycles with fresh spermatozoa $(p=0.011)$, there were no significant differences in embryo cleavage rates (95.5\% vs. $98.6 \%, p=0.256)$. Similarly, cycles with fresh spermatozoa showed a significantly greater mean number of day-3 embryos $(p=0.015)$ and higher quality embryos at day-3 $(p=0.011)$, but no significant differences were observed in relation to the rate of high quality embryos ( $81.7 \%$ vs. $77.6 \%, p=0.509)$. No significant differences were found in the mean number of blastocysts $(p=0.200)$ or in blastocyst formation rates (50.8\% vs. $56.5 \%, 0.641)$.

In relation to clinical outcomes (Table 3), there were no significant differences between fresh and cryopreserved spermatozoa regarding the mean number of transferred embryos $(p=0.267)$; significant differences were observed in biochemical pregnancy $(65.2 \%$ vs. $33.3 \%, p=0.035)$, clinical pregnancy $(60.9 \%$ vs. $19 \%, p=0.005)$, implantation (37\% vs. $13.2 \%, p=0.014)$, and live birth rates $(52.2 \%$ vs. $19 \%, p=0.023)$. No significant differences were found in the rates of singletons $(78.6 \%$ vs. $75 \%, p=0.880)$ or twins $(21.4 \%$ vs. $25 \%, p=0.880)$. There were no ectopic pregnancies or stillbirths. Two singleton abortions occurred 
Table 2. ICSI embryological outcomes of patients with non-mosaic Klinefelter syndrome using fresh and frozen-thawed testicular spermatozoa.

\begin{tabular}{|c|c|c|c|c|}
\hline \multirow[b]{2}{*}{ Parameters } & \multicolumn{2}{|c|}{ TESE/ICSI } & \multirow[b]{2}{*}{$p$ value } & \multirow[b]{2}{*}{ Total } \\
\hline & Fresh sperm & $\begin{array}{c}\text { Cryopreserved } \\
\text { sperm }\end{array}$ & & \\
\hline Cycles (n) & 25 & 22 & - & 47 \\
\hline Embryo transfer cycles $(n)$ & 23 & 2 & - & 44 \\
\hline $\operatorname{COC}(n$, mean $\pm S D$, range $)$ & $259(10.4 \pm 5.1) 2-19$ & $202(9.2 \pm 4.7) 2-19$ & 0.419 & $461(9.8 \pm 4.9) 2-19$ \\
\hline MII $(n$, mean $\pm S D$, range $)$ & $208(8.3 \pm 5.0) 1-18$ & $166(7.5 \pm 3.9) 2-18$ & 0.561 & $374(8.0 \pm 4.5) 1-18$ \\
\hline Maturity rate $(\% ; \mathrm{MII} / \mathrm{COC})$ & $80.3 \%(208 / 259)$ & $82.2 \%(166 / 202)$ & 0.611 & $81.1 \%(374 / 461)$ \\
\hline $2 \mathrm{PN} / 2 \mathrm{~PB}(\mathrm{n}$, mean $\pm S D$, range $)$ & $132(5.3 \pm 3.5) 0-14$ & $69(3.1 \pm 1.8) 0-7$ & 0.013 & $201(4.3 \pm 3.0) 0-14$ \\
\hline Fertilization rate (2PN/MII) & $63.5 \%(132 / 208)$ & $41.6 \%(69 / 166)$ & 0.256 & $53.7 \%(201 / 374)$ \\
\hline Cleaved embryos ( $n$, mean \pm SD, range) & $126(5.3 \pm 3.1) 1-14$ & $68(3.2 \pm 1.6) 1-6$ & 0.011 & $194(4.3 \pm 2.7) 1-14$ \\
\hline Embryo cleavage rate $(\%, \mathrm{~d} 2 / 2 \mathrm{PN})$ & $95.5(126 / 132)$ & $98.6(68 / 69)$ & 0.256 & $96.5(194 / 201)$ \\
\hline Day 3 embryos ( $n$, mean \pm SD, range) & $126(5.3 \pm 3.1) 1-14$ & $58(3.2 \pm 1.4) 1-6$ & 0.015 & $184(4.4 \pm 2.7) 1-14$ \\
\hline Day 3 grade A/B embryos ( $n$, mean $\pm S D$, range) & $103(4.5 \pm 2.9) 1-13$ & $45(2.5 \pm 1.2) 1-6$ & 0.011 & $148(3.6 \pm 2.5) 1-13$ \\
\hline Day 3 Grade $A / B$ rate $(A B / d 3)$ & $103 / 126(81.7)$ & $45 / 58(77.6)$ & 0.509 & $148 / 184(80.4)$ \\
\hline Day 5 embryos ( $n$, mean $\pm S D$, range) & $40(4.4 \pm 2.8) 2-9$ & $13(2.6 \pm 1.3) 2-5$ & 0.200 & $53(3.8 \pm 2.5) 2-9$ \\
\hline Blastocyst rate ( $\%$, day $5 /$ day 2 ) & $50.8(31 / 61)$ & $56.6(13 / 23)$ & 0.641 & $52.4(44 / 84)$ \\
\hline
\end{tabular}

TESE=testicular sperm extraction

ICSI $=$ intracytoplasmic sperm injection

TESE/ICSI-fresh sperm=TESE/ICSI cycles using fresh testicular sperm

TESE/ICSI-cryopreserved sperm=TESE/ICSI cycles using cryopreserved testicular sperm

COC $=$ cumulus-oocyte complexes

MII = mature oocytes

$2 \mathrm{PN} / 2 \mathrm{~PB}=2$ pronuclei and 2 polar bodies (normal fertilized oocytes)

$\mathrm{D} 2=$ cleaved embryos at day 2.

Significant differences $(p<0.05)$ between TESE/ICSI with fresh sperm and TESE/ICSI with cryopreserved sperm.

Table 3. ICSI clinical outcomes of patients with non-mosaic Klinefelter syndrome using fresh and frozen-thawed testicular spermatozoa.

\begin{tabular}{|c|c|c|c|c|}
\hline \multirow[b]{2}{*}{ Parameters } & \multicolumn{2}{|c|}{ TESE/ICSI } & \multirow[b]{2}{*}{$p$ value } & \multirow[b]{2}{*}{ Total } \\
\hline & Fresh sperm & $\begin{array}{c}\text { Cryopreserved } \\
\text { sperm }\end{array}$ & & \\
\hline Cycles (n) & 25 & 22 & - & 47 \\
\hline Embryo transfer cycles $(n)$ & 23 & 2 & - & 44 \\
\hline $\mathrm{N}^{\circ}$ of transferred embryos ( $\mathrm{n}$, mean $\pm \mathrm{SD}$, range) & $46(2.0 \pm 0.6) 1-3$ & $38(1.8 \pm 0.5) 1-3$ & 0.267 & $84(1.9 \pm 0.6) 1-3$ \\
\hline Biochemical pregnancy (/ETC) (rate, n) & $65.2 \%(15 / 23)$ & $33.3(7 / 21)$ & 0.035 & $50(22 / 44)$ \\
\hline Clinical pregnancy $(/$ ETC) $($ rate, $n)$ & $60.9(14 / 23)$ & $19(4 / 21)$ & 0.005 & $40.9(18 / 44)$ \\
\hline Sacs $(n)$ & 17 & 5 & - & 22 \\
\hline Implantation rate $\left(\mathrm{n}^{\circ} \mathrm{sacs} / \mathrm{n}^{\circ} \mathrm{ET}\right)$ & $37(17 / 46)$ & $13.2(5 / 38)$ & 0.014 & $26.2(22 / 84)$ \\
\hline Singletons $(/ C P)($ rate, $n)$ & $78.6(11 / 14)$ & $75(3 / 4)$ & 0.880 & $77.8(14 / 18)$ \\
\hline Twins (/CP) (rate, n) & $21.4(3 / 14)$ & $25 \%(1 / 4)$ & 0.880 & $22.2(4 / 18)$ \\
\hline Abortion (/CP) (rate, n) & $14.3(2 / 14)$ & 0 & - & $11.1(2 / 18)$ \\
\hline LBDR (/ETC) (rate, n) & $52.2(12 / 23)$ & $19(4 / 21)$ & 0.023 & $36.4(16 / 44)$ \\
\hline
\end{tabular}

TESE =testicular sperm extraction

ICSI $=$ intracytoplasmic sperm injection,

TESE/ICSI-fresh sperm=TESE/ICSI cycles using fresh testicular sperm

TESE/ICSI-cryopreserved sperm=TESE/ICSI cycles using cryopreserved testicular sperm

$\mathrm{ETC}=$ embryo transfer cycles,

$\mathrm{ET}=$ number of transferred embryos

$\mathrm{CP}=$ clinical pregnancy

LBDR=live birth delivery rate.

Significant differences $(p<0.05)$ between TESE/ICSI with fresh sperm and TESE/ICSI with cryopreserved sperm. 
in cycles with fresh spermatozoa. Of the 44 embryo transfer cycles, $4(9.1 \%)$ were performed on Day $2 ; 19(43.2 \%)$ on Day $3 ; 8(18.2 \%)$ on Day 4 ; and $13(29.5 \%)$ on Day 5. The relative clinical pregnancy rates were $42.1 \%(8 / 19)$ on Day $3 ; 25 \%(2 / 8)$ on Day 4 ; and $61.5 \%(8 / 13)$ on Day 5; no pregnancies were achieved through embryo transfers on Day 2. The day of embryo transfer was generally similar between cycles with fresh and cryopreserved spermatozoa, as follows: Day 2 (4.3\% vs. $14.3 \%)$; Day $3(43.5 \%$ vs. $42.9 \%)$; Day 4 (17.4\% vs. $19 \%)$; and Day $5(34.8 \%$ vs. $23.8 \%)$. However, pregnancies rates were dissimilar: Day 2 (0\% vs. 0\%); Day 3 (70\% vs. $11.1 \%)$; Day $4(0 \%$ vs. $50 \%)$; and Day 5 (87.5\% vs. $20 \%)$.

Concerning live births (Table 4), cycles with fresh spermatozoa yielded significantly higher live birth rates (65.2\% vs. $23.8 \%, p=0.006)$. There were no significant differences regarding gestation age $(p=0.444)$. Another healthy child was born after a frozen-thawed embryo transfer cycle, belonging to the fresh group (caesarean delivery at 39 weeks of gestation, female newborn). There were more female $(70 \%)$ than male $(30 \%)$ newborns. None of the newborns presented malformations; all had normal numerical chromosome constitutions for chromosomes 13, 18, 21, $\mathrm{X}$ and Y. Amniocentesis was performed in 3 cases and normal fetal karyotypes were confirmed. Early neonatal death (< 7 days after birth) occurred in the fresh testicular sperm group, apparently due to an abnormal insertion of the placenta (eutocic delivery at 36 weeks of gestation, male newborn, after transfer of 2 blastocysts, whose mother and father were aged 26 and 29 years, respectively). Almost a fifth $(18.8 \%)$ of the 16 deliveries were preterm; $8.3 \%$ of them (36 weeks) were born from cycles with fresh spermatozoa and $50 \%$ ( 34 and 35 weeks) from cycles with cryopreserved spermatozoa. More than a third of the newborns $(36.8 \%)$ had low birth weight; $35.7 \%$ of them were born from cycles with fresh spermatozoa, and $66.7 \%$ from cycles with cryopreserved spermatozoa.

\section{DISCUSSION}

The study population belongs to a special non-mosaic KS phenotype. These patients, besides infertility, did not show any signs or symptoms of testosterone deficiency. Most men had decreased mean testicular volume and their hormone profiles confirmed high mean serum levels of FSH and $\mathrm{LH}$, with normal mean testosterone values in most of the cases. Patients with KS may present mild physical abnormalities, a possible explanation for why they do not receive clinical attention until they seek medical advice for infertility as adults (Bonomi et al., 2017). Our series gives further evidence of the clinical and hormonal heterogeneity of $\mathrm{KS}$ in patients visiting infertility clinics.

We did not find significant differences between patients with and without successful sperm retrieval (SSR) in terms of age, time of infertility, testicular volume, or serum hormone levels. Our results were similar to the ones published in previous studies (Madureira et al., 2014; Vicdan et al., 2016; Corona et al., 2017). However, other studies described higher sperm retrieval rates (SRR) associated with lower mean age (Okada et al., 2005a; Emre Bakircioglu et al., 2006; Ozer et al., 2018), lower FSH, and higher testosterone levels (Ozer et al., 2018).

Microsurgical TESE (Schlegel, 1999) was developed to yield higher SSR rates. Although exhibiting a variable range of success, several reports have evidenced higher SRR rates with microsurgical TESE (MTESE) than conventional TESE (CTESE) (Chen et al., 2019). However, some studies did not confirm higher SRR rates in mTESE (Guo et al., 2020). Comparisons between the two methods were recently reviewed. A meta-analysis involving $1248 \mathrm{KS}$ patients showed no significant differences in SSR rates between the two methods, with a mean SRR rate of $44 \%$ ( $43 \%$ in cTESE, $45 \%$ in mTESE, $41 \%$ in mixed cases) (Corona et al., 2017). A more recent literature review including KS patients also reported SRR rates of $42-57 \%$ using both methods of testicular sperm retrieval (Chen et al., 2020). These differences stress the fact that SSR variability might not be due only to the different number of patients studied or the retrieval technique, but also to differences in patient characteristics. Along these lines, in our special group of KS patients the calculated SRR rate of $40.3 \%$ is comparable with previous reports using either cTESE or MTESE.

In the present report, there were 47 ICSI treatment cycles, 25 with fresh and 22 with cryopreserved testicular spermatozoa. No significant differences were observed between both groups in relation to the rates of oocyte maturity, embryo cleavage, high quality embryos and blastocyst formation. However, there were significantly higher

\begin{tabular}{|c|c|c|c|c|}
\hline \multirow{2}{*}{ Parameters } & \multicolumn{2}{|c|}{ TESE/ICSI } & \multirow{2}{*}{$p$ value } & \multirow{2}{*}{ Total } \\
\hline & Fresh sperm & Cryopreserved sperm & & \\
\hline Cycles (n) & 25 & 22 & - & 47 \\
\hline Embryo transfer cycles $(n)$ & 23 & 2 & - & 44 \\
\hline Newborn (/ETC) (rate, n) & $65.2(15 / 23)$ & $23.8(5 / 21)$ & 0.006 & $45.5(20 / 44)$ \\
\hline Male $(/ N B)($ rate, $n)$ & $26.7(4 / 15)$ & $40(2 / 5)$ & 0.573 & $30(6 / 20)$ \\
\hline Female (/NB) (rate, $\mathrm{n})$ & $73.3(11 / 15)$ & $60(3 / 5)$ & 0.573 & $70(14 / 20)$ \\
\hline NB malformations (/NB) (rate, $n$ ) & 0 & 0 & - & 0 \\
\hline EN death (/ETC) (n, rate) ( $\leq 7$ days after birth) & $4.3(1 / 23)$ & 0 & - & $2.3(1 / 44)$ \\
\hline Gestational age (mean $\pm S D$, range) & $37.9 \pm 1.7(34-40)$ & $37.0 \pm 2.9(34-40)$ & 0.444 & $37.7 \pm 2.0(34-40)$ \\
\hline
\end{tabular}

TESE=testicular sperm extraction

ICSI =intracytoplasmic sperm injection

TESE/ICSI-fresh sperm=TESE/ICSI cycles using fresh testicular sperm

TESE/ICSI-cryopreserved sperm=TESE/ICSI cycles using cryopreserved testicular sperm

$\mathrm{ETC}=$ embryo transfer cycles, $\mathrm{NB}=$ newborn

EN death=early neonatal death.

Significant differences $(p<0.05)$ between TESE/ICSI with fresh sperm and TESE/ICSI with cryopreserved sperm. 
fertilization, biochemical pregnancy, clinical pregnancy, implantation, and live birth rates in the fresh spermatozoa group.

Several previous studies reported the use of cryopreserved testicular spermatozoa (Ron-El et al., 2000a; Friedler et al., 2001; Bergère et al., 2002; Westlander et al., 2003; Okada et al., 2005b; Kyono et al., 2007; Vicdan et al., 2007; Greco et al., 2008), but they consisted of small case series or single case reports. Three recent studies provided larger numbers of patients and enabled clearer comparisons between fresh and cryopreserved spermatozoa treatment cycles. In a report with $38 \mathrm{KS}$ patients with an SRR rate of $39.5 \%$ using CTESE and MTESE, 10 fresh and 16 cryopreserved testicular spermatozoa treatment cycles were performed. The authors observed a significant higher embryo cleavage rate in ICSI performed with cryopreserved testicular spermatozoa (Greco et al., 2013). In a previous report by our group including $65 \mathrm{KS}$ patients with an SRR rate of $38.5 \%$ using cTESE, 20 fresh and 17 cryopreserved testicular spermatozoa treatment cycles were performed. The authors observed significantly higher rates of fertilization, high quality embryos, and clinical pregnancy in ICSI cycles using fresh testicular spermatozoa (Madureira et al., 2014). In another report including $83 \mathrm{KS}$ patients with an SRR rate of $42.1 \%$ using CTESE and mTESE, 32 fresh and 12 cryopreserved testicular spermatozoa treatment cycles were performed. The authors observed a significantly higher implantation rate in ICSI with cryopreserved testicular spermatozoa (Vicdan et al., 2016). In conclusion, two studies indicated that ICSI cycles with cryopreserved testicular spermatozoa were associated with higher rates of embryo cleavage and implantation, while two studies (including the result reported herein) found that ICSI cycles using fresh testicular spermatozoa were associated with higher fertilization, embryo cleavage, high quality embryo, implantation, pregnancy, and live birth rates.

These differences deserve some attention. First, in a meta-analysis including cases of non-obstructive azoospermia, the authors found no significant differences in embryological or clinical outcomes from ICSI using either cryopreserved or fresh testicular spermatozoa. However, the authors also observed that better outcomes were reached with fresh testicular sperm when different diseases were individually analyzed (Ohlander et al., 2014). Regarding the surprising observations that the use of cryopreserved testicular spermatozoa yielded higher embryo cleavage and implantation rates (Greco et al., 2013; Vicdan et al., 2016), since only two parameters were analyzed and the number of cases included was relatively low, data may indicate that in reality there are no critical clinical differences between ICSI outcomes either using fresh or cryopreserved testicular spermatozoa.

In relation to previous observations (Madureira et al., 2014) and findings of the present study that support better embryological and clinical outcomes with fresh testicular spermatozoa than with cryopreserved testicular spermatozoa, some hypotheses can be raised regarding the conclusion described in the meta-analysis in which no differences were found in embryological and clinical outcomes when fresh and cryopreserved testicular spermatozoa were compared (Ohlander et al., 2014). First, this meta-analysis included all types of non-obstructive azoospermia, and not only individuals with KS. Secondly, we may assume that the present results may be due to the greater number of cases studied with cryopreserved testicular spermatozoa and/or the specific KS population analyzed. Another hypothesis might be the lower quality of cryopreserved spermatozoa retrieved from diagnostic TESE. However, comparisons between TESE and diagnostic TESE revealed no differences between the two (data not shown), besides the fact that only five cycles were performed with cryopreserved spermatozoa from diagnostic TESE.

In KS patients, spermatozoa (Ferlin et al., 2005) and preimplantation embryos (Staessen et al., 2003) exhibit a higher rate of autosome and sex chromosome aneuploidies. There are two reports with fetal reduction due to a 47,XXY karyotype after ART treatments (Ron-El et al., 2000b; Friedler et al., 2001). Nevertheless, all published data revealed that, with the exception of these two cases, none of the newborns from KS patients showed abnormal chromosomal constitutions (Madureira et al., 2014; Corona et al., 2017; 2019; Miki et al., 2017; Chen et al., 2020). This clearly reassures couples that men with $\mathrm{KS}$ are not at increased risk of transmitting their genetic condition to their offspring. The birth of healthy children from KS patients using testicular spermatozoa may be explained by observations that the majority of the $47, X X Y$ germ cells are not meiotically competent. Additionally, studies also showed that a normal pattern of sex chromosome segregation occurs in most of the testicular spermatozoa retrieved from KS patients (Garcia-Quevedo et al., 2011; Miki et al., 2017). In the present study, 21 healthy children were born without numerical chromosomal abnormalities.

\section{CONCLUSION}

The data described herein account for one of the largest series of azoospermic patients with non-mosaic Klinefelter syndrome studied to date and of Klinefelter syndrome patients treated with cryopreserved testicular spermatozoa. After conventional TESE, the spermatozoa recovery rate was $40.3 \%$, which is similar to the rates presented in most recent literature. Analysis of the clinical outcomes revealed high pregnancy and live birth rates, with all 21 newborns presenting no malformations or chromosomal aneuploidies. These results are very encouraging for the reproductive prognosis of non-mosaic Klinefelter syndrome patients. Future studies with a greater number of cycles using cryopreserved testicular spermatozoa are needed in order to confirm the existence of better clinical outcomes with fresh testicular spermatozoa.

FUNDING: This research did not receive any specific grant from funding agencies in the public, commercial, or not-for-profit sectors. The Unit for Multidisciplinary Research in Biomedicine (UMIB) is funded by the Foundation for Science and Technology (FCT) Portugal (grant numbers UIDB/00215/2020, and UIDP/00215/2020) and ITR - Laboratory for Integrative and Translational Research in Population Health (LA/P/0064/2020).

\section{ACKNOWLEDGEMENTS}

The authors would like to thank the members of the Genetics and IVF units for their invaluable assistance.

\section{CONFLICT OF INTEREST}

The authors declare no conflict of interest.

\section{Corresponding author}

Mário Sousa

Laboratory of Cell Biology (Director)

Department of Microscopy

Institute of Biomedical Sciences Abel Salazar (ICBAS), University of Porto (UP).

Porto, Portugal

E-mail: msousa@icbas.up.pt

ORCID ID: https://orcid.org/0000-0002-3009-3290

CIÊNCIA ID: 5118-4AC0-9709

Portuguese Physicians Order N. ${ }^{\circ}: 30027$ 


\section{REFERENCES}

Aksglaede L, Wikström AM, Rajpert-De Meyts E, Dunkel $L$, Skakkebaek NE, Juul A. Natural history of seminiferous tubule degeneration in Klinefelter syndrome. Hum Reprod Update. 2006;12:39-48. PMID: 16172111 DOI: 10.1093/ humupd/dmi039

Alpha Scientists in Reproductive Medicine and ESHRE Special Interest Group of Embryology. The Istanbul consensus workshop on embryo assessment: proceedings of an expert meeting. Hum Reprod. 2011;26:1270-83. PMID: 21502182 DOI: 10.1093/humrep/der037

Bergère $M$, Wainer $R$, Nataf $V$, Bailly $M$, Gombault $M$, Ville $Y$, Selva J. Biopsed testis cells of four $47, X X Y$ patients: fluorescence in-situ hybridization and ICSI results. Hum Reprod. 2002;17:32-7. PMID: 11756358 DOI: 10.1093/ humrep/17.1.32

Bonomi M, Rochira V, Pasquali D, Balercia G, Jannini EA, Ferlin A; Klinefelter ItaliaN Group (KING). Klinefelter syndrome (KS): genetics, clinical phenotype and hypogonadism. J Endocrinol Invest. 2017;40:123-34. PMID: 27644703 DOI: $10.1007 / \mathrm{s} 40618-016-0541-6$

Bujan L, Mieusset R, Mansat A, Moatti JP, Mondinat C, Pontonnier $F$. Testicular size in infertile men: relationship to semen characteristics and hormonal blood levels. Br J Urol. 1989;64:632-7. PMID: 2516757 DOI: $10.1111 /$ j.1464410X.1989.tb05325.x

Chen W, Bai MZ, Yang Y, Sun D, Wu S, Sun J, Wu Y, Feng Y, Wei Y, Chen Z, Zhang Z. ART strategies in Klinefelter syndrome. J Assist Reprod Genet. 2020;37:2053-79. PMID: 32562095 DOI: $10.1007 /$ s10815-020-01818-2

Chen X, Ma Y, Zou S, Wang S, Qiu J, Xiao Q, Zhou L, Ping $P$. Comparison and outcomes of nonobstructive azoospermia patients with different etiology undergoing microTESE and ICSI treatments. Transl Androl Urol. 2019;8:366-73. PMID: 31555560 DOI: 10.21037/tau.2019.04.08

Corona G, Pizzocaro A, Lanfranco F, Garolla A, Pelliccione $F$, Vignozzi L, Ferlin A, Foresta C, Jannini EA, Maggi M, Lenzi A, Pasquali D, Francavilla S; Klinefelter ItaliaN Group (KING). Sperm recovery and ICSI outcomes in Klinefelter syndrome: a systematic review and meta-analysis. Hum Reprod Update. 2017;23:265-75. PMID: 28379559 DOI: $10.1093 /$ humupd/dmx008

Corona G, Minhas S, Giwercman A, Bettocchi C, Dinkelman-Smit M, Dohle G, Fusco F, Kadioglou A, Kliesch $S$, Kopa Z, Krausz C, Pelliccione F, Pizzocaro A, Rassweiler J, Verze P, Vignozzi L, Weidner W, Maggi M, Sofikitis N. Sperm recovery and ICSI outcomes in men with non-obstructive azoospermia: a systematic review and meta-analysis. Hum Reprod Update. 2019;25:733-57. PMID: 31665451 DOI: 10.1093/humupd/dmz028

Crabbé E, Verheyen G, Tournaye H, Van Steirteghem A. The use of enzymatic procedures to recover testicular germ cells. Hum Reprod. 1997;12:1682-7. PMID: 9308793 DOI: $10.1093 /$ humrep/12.8.1682
Crabbé E, Verheyen G, Silber S, Tournaye H, Van de Velde $H$, Goossens A, Van Steirteghem A. Enzymatic digestion of testicular tissue may rescue the intracytoplasmic sperm injection cycle in some patients with non-obstructive azoospermia. Hum Reprod. 1998;13:2791-6. PMID: 9804232 DOI: $10.1093 /$ humrep/13.10.2791

Emre Bakircioglu M, Erden HF, Kaplancan T, Ciray N, Bener F, Bahceci M. Aging may adversely affect testicular sperm recovery in patients with Klinefelter syndrome. Urology. 2006;68:1082-6. PMID: 17095066 DOI: 10.1016/j.urology.2006.05.028

Ferlin A, Garolla A, Foresta C. Chromosome abnormalities in sperm of individuals with constitutive sex chromosomal abnormalities. Cytogenet Genome Res. 2005;111:310-6. PMID: 16192710 DOI: https://doi.org/10.1159/000086905

Friedler S, Raziel A, Strassburger D, Schachter M, Bern O, RonEI R. Outcome of ICSI using fresh and cryopreserved-thawed testicular spermatozoa in patients with non-mosaic Klinefelter's syndrome. Hum Reprod. 2001;16:2616-20. PMID: 11726584 DOI: 10.1093/humrep/16.12.2616

Garcia-Quevedo L, Blanco J, Sarrate Z, Català V, Bassas $L$, Vidal $F$. Hidden mosaicism in patients with Klinefelter's syndrome: implications for genetic reproductive counselling. Hum Reprod. 2011;26:3486-93. PMID: 22016414 DOI: $10.1093 /$ humrep/der351

Gardner DK, Lane M, Stevens J, Schlenker T, Schoolcraft WB. Blastocyst score affects implantation and pregnancy outcome: towards a single blastocyst transfer. Fertil Steril. 2000;73:1155-8. PMID: 10856474 DOI: 10.1016/S00150282(00)00518-5

Gorgy A, Meniru GI, Naumann N, Beski S, Bates S, Craft IL. The efficacy of local anesthesia for percutaneous epididymal sperm aspiration and testicular sperm aspiration. Hum Reprod. 1998;13:646-50. PMID: 9572427 DOI: 10.1093/ humrep/13.3.646

Gravholt CH, Chang S, Walentin M, Fedder J, Moore P, Skakkebaek A. Klinefelter Syndrome: Integrating Genetics, Neuropsychology, and Endocrinology. Endocr Rev. 2018;39:289423. PMID: 29438472 DOI: 10.1210/er.2017-00212

Greco E, Iacobelli M, Rienzi L, Fabris GFM, Tesorio N, Tesarik J. Birth of a healthy boy after fertilization of cryopreserved oocytes with cryopreserved testicular spermatozoa from a man with nonmosaic Klinefelter syndrome. Fertil Steril. 2008;89:991.e5-e7. PMID: 17980871 DOI: $10.1016 /$ j.fertnstert.2007.04.039

Greco E, Scarselli F, Minasi MG, Casciani V, Zavaglia D, Dente D, Tesarik J, Franco G. Birth of 16 healthy children after ICSI in cases of nonmosaic Klinefelter syndrome. Hum Reprod. 2013;28:1155-60. PMID: 23493114 DOI: 10.1093 /humrep/det046

Groth KA, Skakkebaek A, Høst C, Gravholt CH, Bojesen A. Clinical review: Klinefelter syndrome - a clinical update. J Clin Endocrinol Metab. 2013;98:20-30. PMID: 23118429 DOI: $10.1210 /$ jc. 2012-2382 
Guo F, Fang A, Fan Y, Fu X, Lan Y, Liu M, Cao S, An G. Role of treatment with human chorionic gonadotropin and clinical parameters on testicular sperm recovery with microdissection testicular sperm extraction and intracytoplasmic sperm injection outcomes in 184 Klinefelter syndrome patients. Fertil Steril. 2020;114:997-1005. PMID: 32868102 DOI: $10.1016 /$ j.fertnstert.2020.05.043

Jacobs PA, Strong JA. A case of human intersexuality having a possible XXY sex-determining mechanism. Nature. 1959;183:302-3. PMID: 13632697 DOI: $10.1038 / 183302 \mathrm{a} 0$

Klinefelter HF, Reifenstein EC, Albright F. Syndrome characterized by gynecomastia, aspermatogenesis without A-Leydigism, and increased excretion of follicle stimulating hormone. J Clin Endocrinol Metab. 1942;2:615-27. DOI: 10.1210/jcem-2-11-615

Kyono K, Uto H, Nakajo Y, Kumagai S, Araki Y, Kanto S. Seven pregnancies and deliveries from non-mosaic Klinefelter syndrome patients using fresh and cryopreserved testicular sperm. J Assist Reprod Genet. 2007;24:47-51. PMID: 17177108 DOI: $10.1007 /$ s10815-006-9079-4

Lanfranco F, Kamischke A, Zitzmann M, Nieschlag E. Klinefelter's syndrome. Lancet. 2004;364:273-83. PMID: 15262106 DOI: $10.1016 /$ S0140-6736(04)16678-6

Li PS, Li S, Schlegel PN, Goldstein M. External spermatic sheath injection for vasal nerve block. Urology. 1992;39:173-6. PMID: 1736514 DOI: 10.1016/00904295(92)90278-5

Madureira C, Cunha M, Sousa M, Neto AP, Pinho MJ, Viana P, Gonçalves A, Silva J, Teixeira da Silva J, Oliveira C, Ferraz L, Dória S, Carvalho F, Barros A. Treatment by testicular sperm extraction and intracytoplasmic sperm injection of 65 azoospermic patients with non-mosaic Klinefelter syndrome with birth of 17 healthy children. Andrology. 2014;2:623-31. PMID: 24954116 DOI: $10.1111 /$ j.20472927.2014.00231.x

Miki T, Nagayoshi M, Takemoto Y, Yamaguchi T, Takeda S, Watanabe S, Tanaka A. Genetic risk of Klinefelter's syndrome in assisted reproductive technology. Reprod Med Biol. 2017; 16:188-95. PMID: 29259468 DOI: 10.1002/ rmb2.12029

Nagy ZP, Verheyen G, Tournaye H, Devroey P, Van Steirteghem AC. An improved treatment procedure for testicular biopsy specimens offers more efficient sperm recovery: case series. Fertil Steril. 1997;68:376-9. PMID: 9240275 DOI: $10.1016 /$ S0015-0282(97)81534-8

Nudell DM, Conaghan J, Pedersen RA, Givens CR, Schriock $E D$, Turek PJ. The mini-micro-epididymal sperm aspiration for sperm retrieval: a study of urological outcomes. Hum Reprod. 1998;13:1260-5. PMID: 9647557 DOI: 10.1093/ humrep/13.5.1260

Ohlander S, Hotaling J, Kirshenbaum E, Niederberger C, Eisenberg ML. Impact of fresh versus cryopreserved testicular sperm upon intracytoplasmic sperm injection pregnancy outcomes in men with azoospermia due to spermatogenic dysfunction: a meta-analysis. Fertil Steril. 2014;101:344-9. PMID: 24345355 DOI: 10.1016/j.fertnstert.2013.10.012
Okada H, Goda K, Yamamoto Y, Sofikitis N, Miyagawa I, Mio $Y$, Koshida $M$, Horie S. Age as a limiting factor for successful sperm retrieval in patients with nonmosaic Klinefelter's syndrome. Fertil Steril. 2005a;84:1662-4. PMID: 16359961 DOI: 10.1016/j.fertnstert.2005.05.053

Okada H, Goda K, Muto S, Maruyama O, Koshida M, Horie $S$. Four pregnancies in nonmosaic Klinefelter's syndrome using cryopreserved-thawed testicular spermatozoa. Fertil Steril. 2005b;84:1508.e13-6. PMID: 16275253 DOI: 10.1016/j.fertnstert.2005.05.033

Ozer C, Aytec PC, Goren MR, Toksoz S, Gul U, Turunk T. Sperm retrieval by microdissection testicular sperm extraction and intracytoplasmic sperm injection outcomes in nonobstructive azoospermic patients with Klinefelter syndrome. Andrologia. 2018;50:e12983. PMID: 29460304 DOI: 10.1111/and.12983

Palermo GD, Schlegel PN, Sills ES, Veeck LL, Zaninovic N, Menendez S, Rosenwaks Z. Births after intracytoplasmic injection of sperm obtained by testicular extraction from men with nonmosaic Klinefelter's syndrome. New Eng J Med. 1998;338:588-90. PMID: 9475766 DOI: 10.1056/ NEJM199802263380905

Pinto F, Oliveira C, Cardoso MF, Teixeira-da-Silva J, Silva J, Sousa M, Barros A. Impact of GnRH ovarian stimulation protocols on intracytoplasmic sperm injection outcomes. Reprod Biol Endocrinol. 2009;7:5. PMID: 19146685 DOI: 10.1186/1477-7827-7-5

Ron-El R, Raziel A, Strassburger D, Schachter M, Bern O, Friedler S. Birth of healthy male twins after intracytoplasmic sperm injection of frozen-thawed testicular spermatozoa from a patient with nonmosaic Klinefelter syndrome. Fertil Steril. 2000a;74:832-3. PMID: 11020535 DOI: $10.1016 /$ S0015-0282(00)00710-X

Ron-El R, Strassburger D, Gelman-Kohan S, Friedler S, Raziel A, Appelma Z. A 47, XXY fetus conceived after ICSI of spermatozoa from a patient with non-mosaic Klinefelter's syndrome: case report. Hum Reprod. 2000b;15:1804-6. PMID: 10920107 DOI: 10.1093/humrep/15.8.1804

Rooney DE, Czepulkowski BH. Human chromosome preparation. Essential techniques. Hoboken: Wiley; 1997.

Schlegel PN, Su LM. Physiological consequences of testicular sperm extraction. Hum Reprod. 1997;12:1688-92. PMID: 9308794 DOI: 10.1093/humrep/12.8.1688

Schlegel PN. Testicular sperm extraction: microdissection improves sperm yield with minimal tissue excision. Hum Reprod. 1999;14:131-5. PMID: 10374109 DOI: 10.1093/ humrep/14.1.131

Schouten JP, McElgunn CJ, Waaijer R, Zwijnenburg D, Diepvens F, Pals G. Relative quantification of 40 nucleic acid sequences by multiplex ligation-dependent probe amplification. Nucleic Acids Res. 2002;30:e57. PMID: 12060695 DOI: $10.1093 /$ nar/gnf056

Sciurano RB, Hisano CVL, Rahn MI, Olmedo SB, Valzacchi GR, Coco R, Solari AJ. Focal spermatogenesis originates in euploid germ cells in classical Klinefelter patients. Hum Reprod. 2009;24:2353-60. PMID: 19443454 DOI: 10.1093/ humrep/dep180 
Sousa M, Cremades N, Silva J, Oliveira C, Ferraz L, Teixeira da Silva J, Viana $P$, Barros A. Predictive value of testicular histology in secretory azoospermic subgroups and clinical outcome after microinjection of fresh and frozen-thawed sperm and spermatids. Hum Reprod. 2002;17:1800-10. PMID: 12093843 DOI: 10.1093/humrep/17.7.1800

Staessen C, Tournaye $H$, Van Assche $E$, Michiels A, Van Landuyt L, Devroey P, Liebaers I, Van Steirteghem A. PGD in $47, X X Y$ Klinefelter's syndrome patients. Hum Reprod Update. 2003;9:319-30. PMID: 12926526 DOI: 10.1093/ humupd/dmg029

Tesarik J, Sousa M. Key elements of a highly efficient intracytoplasmic sperm injection technique: $\mathrm{Ca} 2+$ fluxes and oocyte cytoplasmic dislocation. Fertil Steril. 1995;64:7706. PMID: 7672149 DOI: 10.1016/S0015-0282(16)57853-4

Thomas NS, Hassold TJ. Aberrant recombination and the origin of Klinefelter syndrome. Hum Reprod Update. 2003;9:30917. PMID: 12926525 DOI: $10.1093 /$ humupd/dmg028

Tournaye $\mathrm{H}$, Staessen $\mathrm{C}$, Liebaers I, Van Assche E, Devroey $P$, Bonduelle $M$, Van Steirteghem $A$. Testicular sperm recovery in nine 47, XXY Klinefelter patients. Hum Reprod. 1996;11:1644-9. PMID: 8921109 DOI: $10.1093 /$ oxfordjournals.humrep.a019462

Van Saen D, Vloeberghs V, Gies I, Mateizel I, Sermon K, De Schepper J, Tournaye H, Goossens E. When does germ cell loss and fibrosis occur in patients with Klinefelter syndrome? Hum Reprod. 2018;33:1009-22. PMID: 29684126 DOI: $10.1093 /$ humrep/dey094
Vandervorst M, Liebaers I, Sermon K, Staessen C, De Vos A, Van de Velde H, Van Assche E, Joris H, Van Steirteghem A, Devroey P. Successful preimplantation genetic diagnosis is related to the number of available cumulus-oocyte complexes. Hum Reprod. 1998;13:3169-76. PMID: 9853877 DOI: $10.1093 /$ humrep/13.11.3169

Verheyen G, De Croo I, Tournaye H, Pletincx I, Devroey P, van Steirteghem AC. Comparison of four mechanical methods to retrieve spermatozoa from testicular tissue. Hum Reprod. 1995;10:2956-9. PMID: 8747053 DOI: 10.1093/ oxfordjournals.humrep.a135828

Vicdan K, Akarsu C, Vicdan A, Dingiloğlu B, Sözen E, Coşkun Z, Isik AZ. Births using froze-thawed testicular spermatozoa and frozen-thawed embryos in two azoospermic patients with nonmosaic Klinefelter's syndrome. J Turk Ger Gynecol Assoc. 2007;8:424-7

Vicdan K, Akarsu C, Sözen E, Buluç R, Vicdan A, Yilmaz Y, Biberoğlu K. Outcomes of intracytoplasmic sperm injection using fresh and cryopreserved-thawed testicular spermatozoa in 83 azoospermic men with Klinefelter syndrome. J Obstet Gynaecol Res. 2016;42:1558-66. PMID: 27785898 DOI: https://doi.org/10.1111/jog.13090

Westlander G, Ekerhovd E, Bergh C. Low levels of serum inhibin $B$ do not exclude successful sperm recovery in men with nonmosaic Klinefelter syndrome. Fertil Steril. 2003;79:1680-2. PMID: 12801584 DOI: https://doi. org/10.1016/S0015-0282(03)00403-5

Wikström AM, Dunkel L. Testicular function in Klinefelter syndrome. Horm Res. 2008;69:317-26. PMID: 18504390 DOI: $10.1159 / 000117387$ 